
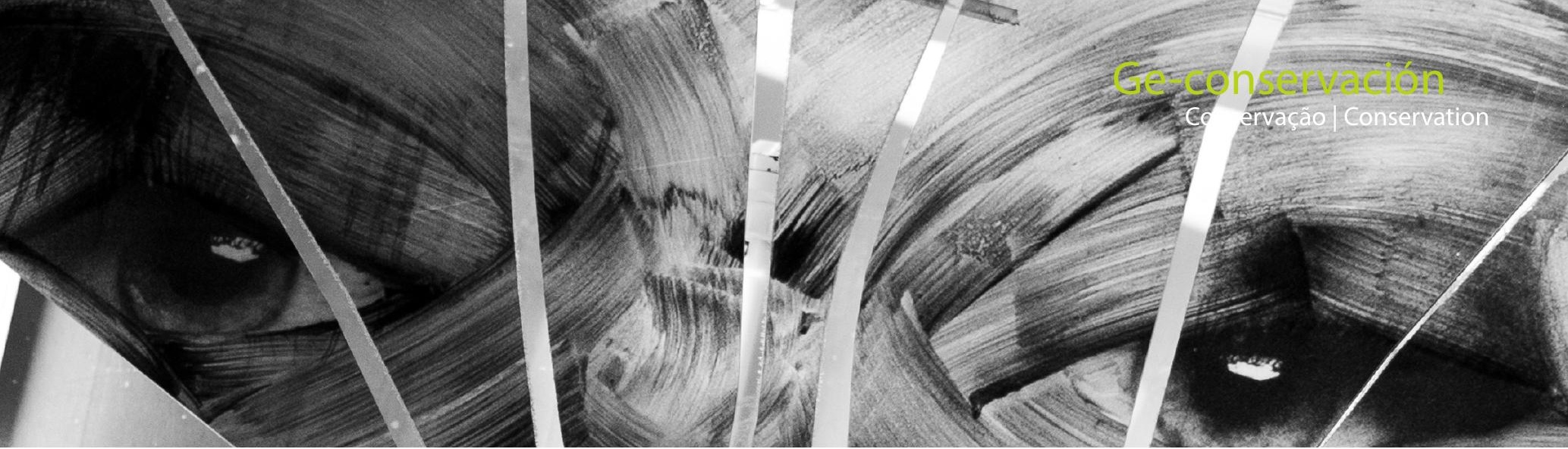

\title{
Repensando el arte público. New York city's Percent for Art Program
}

\author{
Sergio Pardo López
}

Resumen: En los últimos treinta años el número de nuevos programas e iniciativas de arte público se ha incrementado exponencialmente tanto en Estados Unidos como a nivel internacional. El aumento de iniciativas que promueven esta disciplina y la falta de rigurosidad en sus procesos de selección y gestión dificultan la consecución de piezas de arte público exitosas. El siguiente artículo presenta y evalúa diferentes aspectos que facilitan la concepción de piezas de arte público con garantías a través del Percent for Art Program, de la Concejalía de Cultural de Nueva York, programa pionero en la disciplina en Estados Unidos.

Palabras clave: Percent for Art Program, New York, Arte Público, Cultural Policies

\section{Rethiking public art. New York city's Percent For Art Program}

Abstract: In the last thirty years the number of new public art programs and initiatives has increased exponentially both in the United States and internationally. The increase in initiatives that promote this discipline and the lack of rigor in their selection and management processes make it difficult for these programs to achieve public success. The following article presents and evaluates the conception of public art pieces through the Percent for Art Program, of the Department of Cultural Affairs of New York City, a pioneering program in the United States.

Key words: Percent for Art Program, New York, Public Art, Cultural Policies

\section{Introducción}

En palabras de la filósofa de origen alemán Hilde Hein "la presencia de arte al aire libre, bien en una terminal de autobuses o en la recepción de un hotel no hace que el arte sea automáticamente público, al igual que no por el mero hecho de introducir un tigre en una jaula lo podremos llegar a domesticar". (Hilde 1996:4). En las últimas décadas, la presencia de piezas de arte público como resultado de iniciativas aisladas o enmarcadas en programas específicos ha aumentado exponencialmente tanto dentro de nuestras fronteras como a nivel internacional. Sin embargo, la falta de transparencia, la carencia de procesos de selección rigurosos o el descuido en la posterior gestión - en parte de estas iniciativas - ha tenido a corto plazo la consecuencia global de un empobrecimiento de la disciplina.

El éxito del arte público radica en gran parte en la adecuada combinación de tres componentes principales: la elección de propuestas y, por ende, de sus creadores que despierten gran interés artístico, una correcta comprensión del espacio, así como su vinculación con el entorno en donde se ubicará la pieza. Estos tres ejes son esenciales a la hora de responder a la idea principal que debe estar detrás de cualquier proceso de arte en 
el espacio público: ¿Qué debe lograr la presencia de la futura obra? Respuesta que tiene que ver con el mensaje, sus destinatarios y su propósito. Entender y responder correctamente a las premisas de cada proyecto facilita, por tanto, la aceptación del elemento en el lugar y busca construir un sentimiento de pertenencia y empoderamiento por parte de aquellos que vivirán y disfrutarán de la misma. Así bien, esta amalgama de factores ha de llevarse a cabo teniendo siempre presente la valía artística del proyecto y su potencial para enriquecer, expandir y fortificar la disciplina y la trama urbana de nuestras ciudades.

Es hora de hacer un alto en el camino a fin de ahondar en una profunda reflexión sobre esta materia en aras de establecer y determinar unas directrices que no pretendan alentar y llevar a cabo programas que produzcan meramente obras anodinas sin ningún vínculo con sus destinatarios, cuyo único propósito sea favorecer la imagen del patrocinador o artista e, incluso, inundar de imágenes vacuas las plataformas digitales. Es momento de seleccionar trabajos en procesos abiertos, por profesionales expertos en el campo concreto, teniendo siempre presentes las disciplinas en juego: medio ambiente, arquitectura, demografía e idea de permanencia en el tiempo; lo que junto con el proceso creativo del artista lleve a generar una pieza específica para el lugar. Hoy todos los agentes implicados deben promover políticas y programas que escuchen a las partes actoras, que las hagan partícipes en el proceso de selección para que una vez pasado el testigo la obra no sea entendida como un elemento extraño.

\section{Pasado y presente del arte público en EEUU}

En los Estados Unidos la idea contemporánea de introducir arte en el espacio público surge con el denominado Federal Art Project (FAP), creado por el presidente Franklin D. Roosevelt en 1935 a fin de fomentar la industria creativa y crear oportunidades para pintores, muralistas, escultores y artistas gráficos. El proyecto (renombrado en 1939 como Works Progress Administration; WPA) es el germen de los programas de arte público surgidos a finales de la década de los 50 y, por tanto, del centenar de programas que existen en la actualidad: locales, estatales o federales, y que se subvencionan a cargo de un porcentaje del presupuesto de construcción de las obras públicas (Grieve, 2009). Como definió el primer director del FAP, el curador e historiador Holder Cahill,(1880-1960) la visión de la iniciativa era servir como herramienta para incorporar el arte, los artistas y su proceso creativo en la vida cotidiana de las comunidades de todo el país.

A través de la FAP/WAP [1] unos diez mil artistas produjeron alrededor de trescientos cuarenta mil dibujos, pinturas y obras esculpidas, muchas de las cuales aún son visibles en edificios públicos de todo el país (Hapke, 2008:113). Sin embargo, durante este tiempo el arte público no se entendió como la intersección entre el arte, el espacio y la comunidad. Fue la influencia de un movimiento de arte contemporáneo —durante la década de 1980, el arte participativo y las ideas de Jane Jacobs, "community development must be locally informed, human-centric, and holistic" (Jacobs, 1961) - lo que ayudó a configurar la práctica actual del arte público en Estados Unidos.

Este nuevo enfoque artístico fue capaz de abordar elementos que parecían difíciles de manejar en proyectos institucionales durante los años setenta y ochenta. El arte participativo se centró en un compromiso directo con los espectadores a lo largo del proceso creativo, permitiéndoles ser además creadores y editores. Se plantearon nuevas preguntas: ¿en qué medida el trabajo $y$ el proceso de un artista tienen que estar vinculados al contacto directo con la comunidad? A diferencia del arte participativo, en el arte público no existe un enfoque único para lograr el objetivo deseado. La pieza ha de surgir como respuesta del creador al entorno y condicionantes del proyecto, permitiendo a las partes implicadas participar de manera directa o indirecta, dependiendo del proceso creativo del artista, con el fin de producir obras que además de su intrínseco valor estético, cumplan otros propósitos: fomentar sentimiento de comunidad/identidad, mejorar el espacio urbano, abordar problemas sociales, fomentar el cambio social, aportar un valor educativo o favorecer el desarrollo económico. Como señala la historiadora británica Claire Bishop "una obra de arte público se concibe como incompleta si no hay interacción directa o indirecta por parte de los espectadores". Debe entenderse que, como en el arte participativo, la importancia artística debe estar vinculada a la construcción de vínculos sociales a través del significado y la actividad de la comunidad (Bishop 2006).

\section{Percent for Art Program. NYC Department of Cultural Affairs}

En 1982, mientras Nueva York salía de una recesión económica, el alcalde de la ciudad Edward I. Koch inició el Percent for Art Program, posteriormente aprobado por el Ayuntamiento y dependiente de la Concejalía de Cultura de la ciudad. A partir de entonces un uno por ciento (2) del presupuesto de todos los proyectos de construcción de obra nueva o renovaciones financiadas por la ciudad se destina a obras de arte público, realizadas de manera específica para dichos espacios y su entorno. El Programa comenzó en 1983 con el desarrollo de un procedimiento para determinar los proyectos más adecuados, así como con la implantación de un proceso de selección equitativo llevado a cabo por profesionales del sector, abierto al público y con gran participación de la comunidad. Cerca de 430 proyectos han sido completados desde el inicio del programa, alcanzando un montante de noventa millones de dólares destinados a arte público. A lo largo del programa han participado 
entre otros artistas Alice Aycock, Sol Lewitt, Chakaia Booke, Lawrence Weiner o Ursula von Rydingsvard. Desde el año 2002 casi 140 proyectos han sido completados y en la actualidad el programa cuenta con 126 en curso que alcanzan la suma de 23.9 millones de dólares- y serán destinados a la realización de futuras piezas para la ciudad de Nueva York, obras que llevarán la firma de artistas como Hank Willis Thomas, Mierle Laderman Ukeles o Sara Ouhaddou.

\section{Proceso}

Fases del proceso:

1. Licitación del proyecto

2. Comisariado de Artistas

3. Primer panel de selección

4. Segundo panel de selección. Presentación de propuestas

5. Fabricación

6. Instalación

\section{Licitación del proyecto y Comisariado de Artistas}

Cada proyecto comienza en el momento de la licitación de la construcción y a partir de ahí se inserta en paralelo el trabajo de arquitectos, paisajistas e ingenieros en comunión con el artista. Durante la primera fase el equipo del programa lleva a cabo diferentes reuniones con las partes implicadas: técnicos, miembros de las concejalías involucradas en el proyecto, futuros usuarios del espacio y cohabitantes de la obra, a fin de entender las expectativas y posibles finalidades de la obras. Así mismo, el proyecto es presentado en la Junta de Distrito a fin de involucrar a la comunidad y generar diálogo. Tras un estudio pormenorizado de los condicionantes, el equipo del programa realiza un comisariado de artistas - aproximadamente cuarenta por proyecto - fundamentado únicamente en la trayectoria de los candidatos y su potencial para el proyecto en cuestión, solo teniendo en cuenta su trabajo previo y proceso creativo. Como novedad, factores como la procedencia, el momento en su carrera artística, el valor de mercado o su experiencia previa con la ejecución de obras de arte en el espacio público son del todo irrelevantes, por lo que cualquier artista, con independencia de su trayectoria y ubicación puede postularse como posible candidato.

La selección de artistas es el resultado por tanto de un trabajo interno de comisariado de los miembros del programa, los cuales hacen uso de la base de datos de artistas de la Concejalía de Cultura. Cualquier creador interesado en participar, tanto nacional como internacional, puede postularse durante todo el año a través del portal habilitado y enviar la información necesaria a fin de ser considerado para futuros proyectos [figura 1].

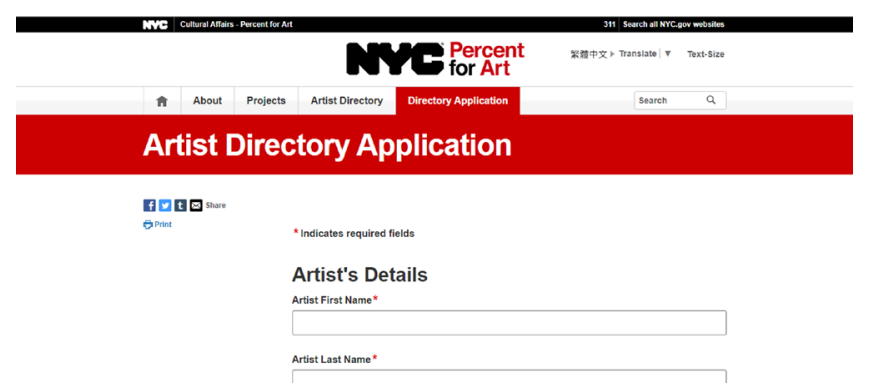

Figura 1.- Captura de pantalla del registro de artistas del Percent for Art Program, accesible dentro de la página web de la Concejalía de Cultural de la ciudad de Nueva York. https://www1.nyc. gov/site/dclapercentforart/contact/contact.page [última consulta:2-11-2019]

\section{Primer y segundo panel de selección}

En las dos fases inmediatamente posteriores de este proceso, del que saldrá el artista elegido, todas las decisiones serán tomadas por técnicos: curadores externos, artistas, críticos especializados en la materia, historiadores, y responsables del programa. Decisiones que tendrán en cuenta los comentarios y puntos de vista de todo aquel que quiera participar, siendo las sesiones abiertas a la participación del público en general. Para cada proyecto, el equipo del programa selecciona los miembros del jurado que participaran en ambos paneles. Los criterios de selección tienen en cuenta la trayectoria del profesional, experiencia en procesos de arte público y su conocimiento del entorno en donde se ubicará la pieza.

\section{Composición el jurado:}

Presidente del jurado: director o miembro del Percent for Art Program

- Panelistas con derecho a voto

- Representante del Percent for Art Program

- Representante de la Sponsor Agency [3]

- Representante de la Design Agency [4]

- 3-4 profesionales externos: artistas, críticos de arte, historiadores o curadores.

- Panelistas Asesores

- Arquitectos, paisajistas, urbanistas, ingenieros

- Representantes de la Public Design Commission [5]

- Representantes políticos: Ayuntamiento, Junta de Distrito

- Organizaciones locales

- Público general

Durante el Primer Panel de Selección el cometido es cribar la lista de cuarenta artistas preseleccionados a cuatro o cinco finalistas, atendiendo a su proceso y potencial creativo. Para ello se presenta a los panelistas diez obras de cada artista acompañado de un Artist Statement [6]. Después de visualizar el trabajo de los artistas a considerar, se abre la ronda de discusión que va seguida por diversas rondas de votación, facilitando la participación de cualquier asistente en la sala a presentar sus alegaciones y puntos de vista. Los 
técnicos con derecho a voto, por tanto, basan su decisión en base tanto a su experiencia y criterio profesional como a los argumentos compartidos por los asistentes y el debate generado durante el proceso.

Tras la selección y posterior comunicado a los finalistas, se organiza en las semanas posteriores una Orientación Artística en donde el equipo del Percent for Art Program, arquitectos, miembros de la comunidad y demás actores involucrados, comparten la información necesaria para la realización de la propuesta específica remunerada por parte de los finalistas. Desde este momento los creadores cuentan con dos meses para desarrollar la idea y contarán con el apoyo de los técnicos Percent for Art Program, que visitarán a los creadores al menos una vez en sus estudios o por a través de videoconferencia un mes antes de la presentación de las propuestas, y demás profesionales involucrados en el proyecto.

El segundo panel de selección o de entrevistas, igualmente abierto al público, el mismo comité escuchará de viva voz durante media hora, ya de manera presencial o por videoconferencia, la presentación por parte de cada uno de los finalistas seleccionados. Debido a la variedad geográfica de los artistas y condicionantes del idioma, la presentación puede ser llevada a cabo por un representante (galerista, miembro del estudio del artista, etc. con la ayuda de intérpretes facilitados por la Concejalía. Tras las presentaciones, al igual que en la primera fase de selección, se abre la ronda de debate y diversas votaciones que tendrán como resultado la selección del artista y proyecto a realizar.

\section{Fabricación e Instalación}

Una vez seleccionada la pieza, comienza la fase de desarrollo de la propuesta, que permitirá al artista(s) definir la idea y abordar tanto aspecto artístico, conceptuales y técnicos con la ayuda de las partes implicadas en el proceso. Siempre que la obra y el proceso creativo a desarrollar lo permitan, se podrán llevar a cabo talleres o actividades en relación a la futura obra, temática y medio artístico, a fin de seguir fomentando el sentimiento de pertenencia y propiedad por parte de la comunidad para con la futura pieza de arte público.

En tal sentido, la visión del Percent for Art Program y su por ende su proceso busca que las piezas seleccionadas pretendan ser una herramienta de expresión y transformación de la comunidad mediante una creación artística colectiva y participativa, surgida del entendimiento de las necesidades, así como de una ubicación concreta y sus adherencias sociales, funcionales, simbólicas y estéticas. Los proyectos de arte público realizados por el programa de Nueva York se materializan en multitud de medios, tamaños, localizaciones y técnicas. Si bien parte de la colección de la ciudad incluye murales, mosaicos y esculturas que se suelen asociar más fácilmente con la concepción más tradicional de "arte público", los proyectos del Percent for Art Program pretenden reflexionar con una visión contemporánea sobre la trama urbana en la que se insertan. Obras como Alterview de Natasha Johns-Messenger que versa sobre las diferentes percepciones de la realidad; Your Voices de Janet Zweig, que funciona como elemento de conexión entre docentes y estudiantes en un colegio público del Bronx; Peace Clock de la artista noruega Lina Viste Grønli, repensando la idea del monumento o memorial con su escultura cinética frente a las Naciones Unidas; o una lámpara de LED, Shakespeare Machine de Ben Rubin que se ha convertido en el icono del vestíbulo del Public Theater, constituyen ejemplos claros de lo que tratan de conseguir. [figura 2]

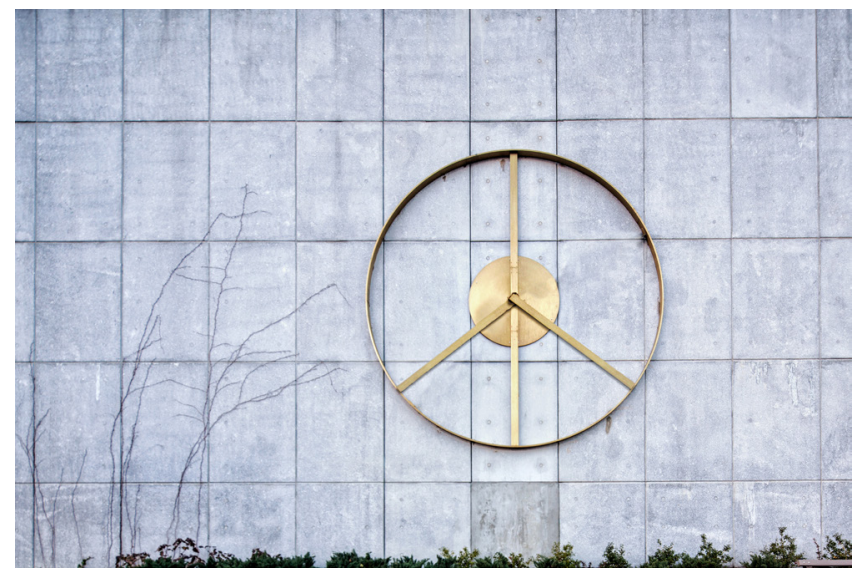

Figura 2.- Obra titulada Peace Clock, realizada en 2019 por la artista Lina Viste Grønli y ubicada en la Trygve Lie Plaza, enfrente de las Naciones Unidas en Manhattan. La pieza en su concepción busca reflexionar sobre cómo ha de abordarse el monumento contemporáneo, buscando conceptos atemporales y transversales en la diversidad de los espectadores, para una mayor relevancia en el tiempo del legado de la persona al que se busca honrar. Peace Clock es una pieza de arte público cinética ubicada delante de las Naciones Unidas que forma el símbolo de la paz dos veces al día (04:30 y 16:30) como tributo a Trygve Lie, primer Secretario General de la organización y promotor de la campaña de desarme nuclear. Concejalía de Cultura de la Ciudad de Nueva York

Tras más de treinta y cinco años de recorrido, el programa neoyorquino sigue marcando la hoja de ruta del arte público en América, y ha logrado sentar unas bases sólidas en cuanto a la necesidad de crear una colección pública con unos criterios abiertos, desde una organización profesionalizada que tiene como objetivo conseguir una muestra contextualizada en su tiempo y lugar, siendo conscientes de que las obras seleccionadas pueden llegar a ser reconocidas como patrimonio cultural. El programa y su proceso han sido adaptados, parcial o totalmente, por otras ciudades americanas, como por ejemplo Seattle o Chicago, y tomado como modelo de referencia por parte de instituciones internacionales con amplio recorrido en la materia, como los de Melbourne y Oslo. 


\section{Algunas de las obras seleccionadas}

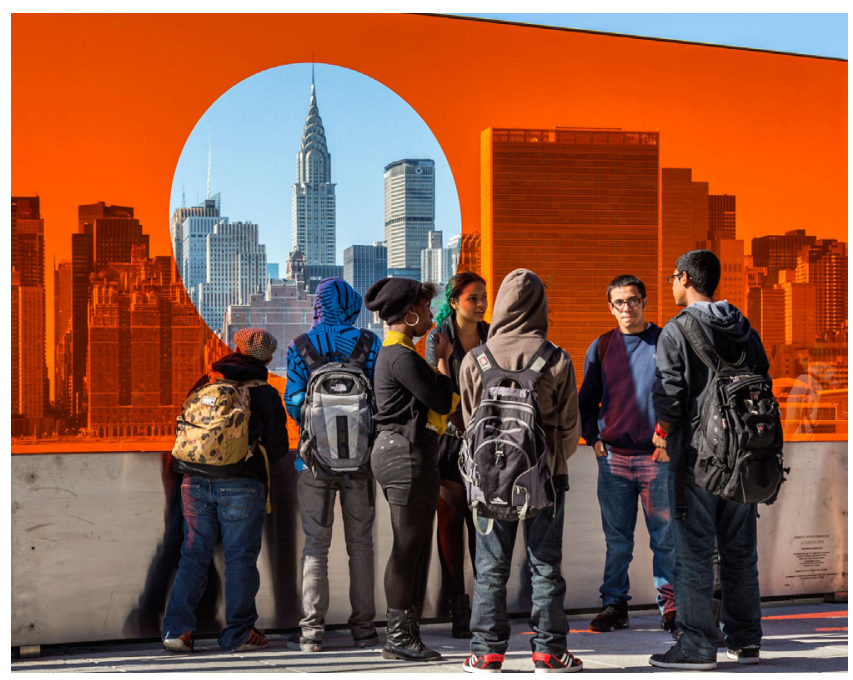

Figura 3.- Artista: Natasha Johns-Messenger; Título: Alterview; Localización: HS/ IS 404, Hunters Point, Queen; Créditos de foto: NYC Department of Cultural Affairs; Breve descripción: Ubicada en la azotea de un instituto público en Queens, la pieza versa sobre las diferentes percepciones de la realidad dependiendo desde donde se miren las cosas.

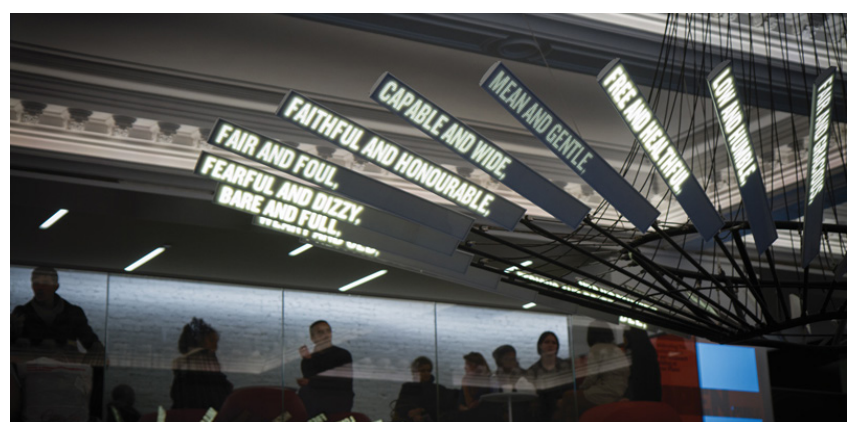

Figura 4.- Artista: Ben Rubin; Título: Shakespeare Machine; Localización: Public Theater, Manhattan; Créditos de foto: NYC Department of Cultural Affairs; Breve descripción: Obra que muestra una selección cambiante de frases de los textos de Shakespeare en el espacio que rinde tributo a su obra y se ha convertido en el icono del teatro público de Nueva York.

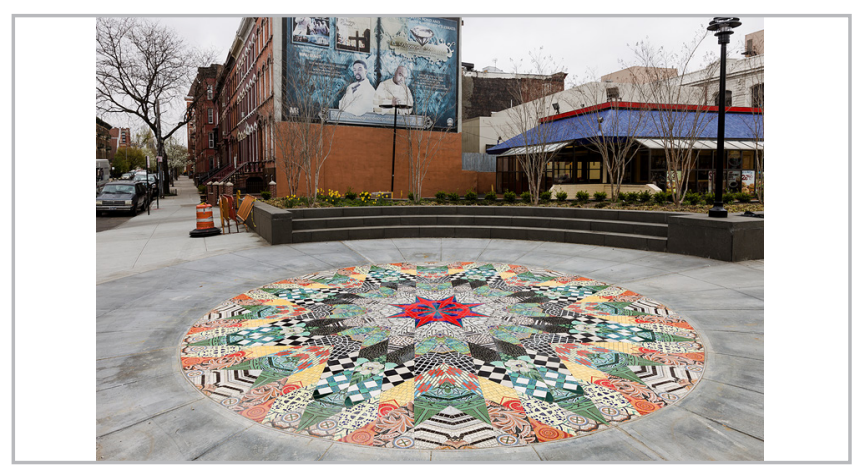

Figura 5.- Artista: Ellen Harvey; Título: Mathematical Star, Localización: Marcy Plaza, Brooklyn; Créditos de foto: NYCDepartment of Cultural Affairs; Breve descripción: Pieza de arte público que funciona en diversos niveles. Por un lado el mosaico recoge la historia del barrio a través de la tradición patchwork incorporando 18 patrones diferentes que hacen referencia a lugares de especial importancia para la comunidad, y por otro genera un nuevo hito con identidad propia. La pieza hoy en día es activada por diferentes organizaciones locales que trabajan con mujeres tras cumplir sus condenas y los hijos de están que han nacido y vivido en prisión, para fomentar sentimiento de identidad y pertenencia en su barrio.

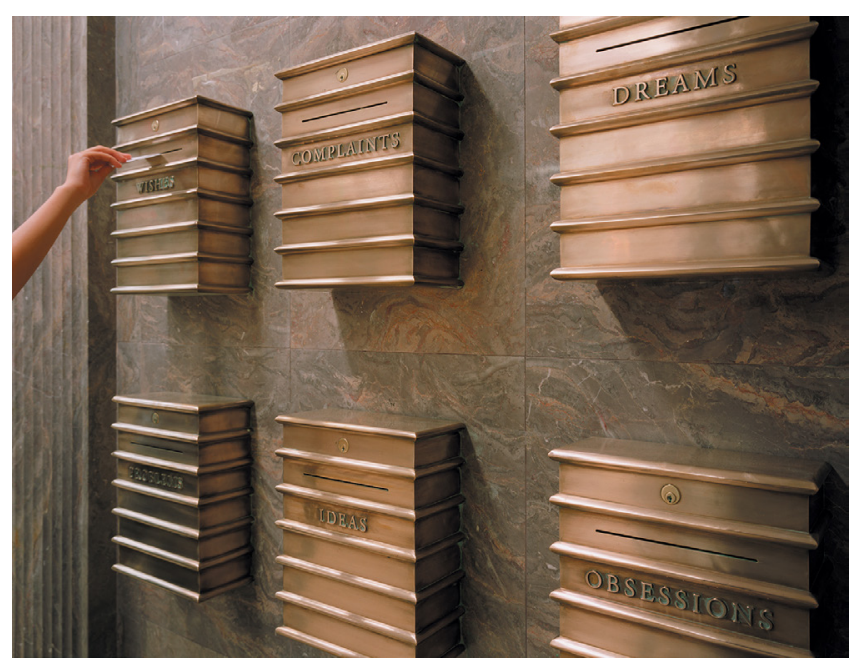

Figura 6.- Artista: Janet Zweig; Título: Your Voices; Localización: Walton High School, Bronx; Créditos de foto: NYC Department of Cultural Affairs; Breve descripción: Obra con un componente participativo que funciona como elemento de conexión entre docentes y estudiantes en un colegio público del Bronx.

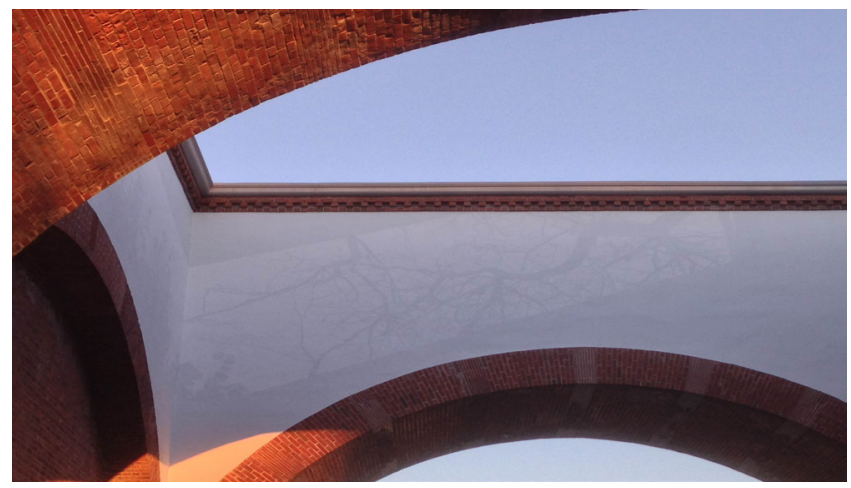

Figura 7.- Artista: Mary Temple; Título: Double Sun; Localización: McCarren Pool, Brooklyn; Créditos de foto: Sergio Pardo López; Breve descripción: Murales que celebran con dos sutiles trampantojos a la entrada del centro deportivo la historia del barrio, los meses de verano y parte de la vegetación perdida del parque.

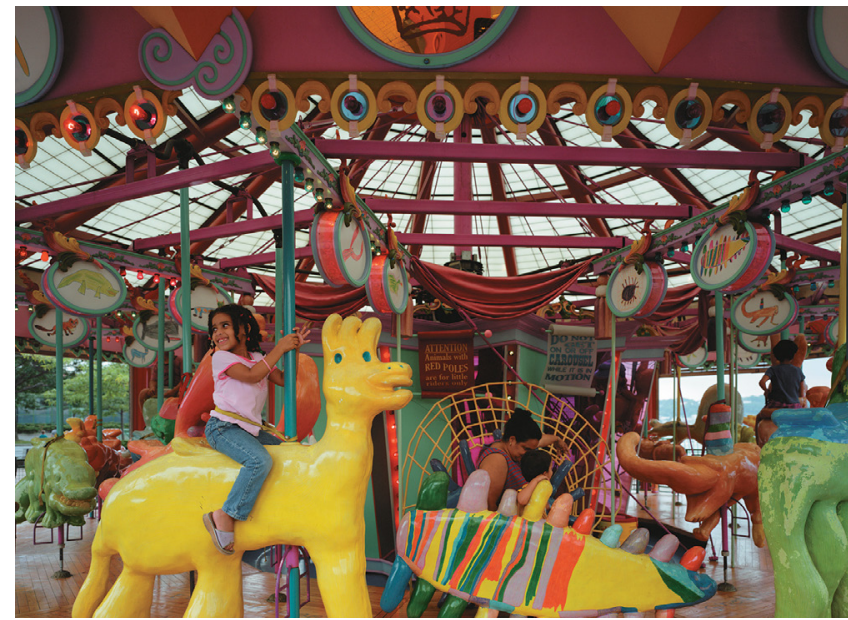

Figura 8.- Artista: Milo Mottola; Título: Totally Kid Carousel; Localización: Riverbank State Park, Manhattan; Créditos de foto: NYC Department of Cultural Affairs. Breve descripción: Pieza creada por el artista con el propósito de revitalizar un parque en desuso y que incorpora el trabajo realizado por el artista con los niños de la zona a fin de generar un sentimiento de propiedad. 


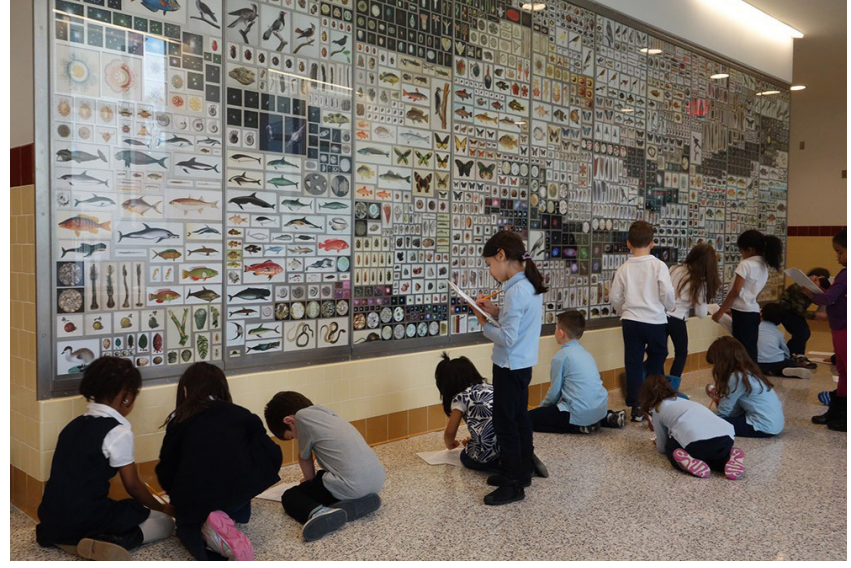

Figura 9.- Artista: Penelope Umbrico; Título: Cabinet 15262013; Localización: PS IS 71, Staten Island; Créditos de foto: NYC Department of Cultural Affairs; Breve descripción: Obra que pretende ser un contrapunto a la sobreexposición de imágenes de la web y presenta en esta enciclopedia de pared o gabinete de curiosidades un complejo mundo de imágenes, grabados y objetos que pretenden incitar a la investigación y el descubrimiento.

\section{Conclusión}

Tanto en sus inicios como en la actualidad, la promoción del sector creativo y la descentralización de la cultura en los cinco barrios de la ciudad de Nueva York siguen facilitando el acceso y visibilidad a piezas artísticas en suelo público y haciendo de esta práctica un catalizador para el diálogo, el compromiso social y el desarrollo económico en cada rincón.

Iniciativas como la expuesta deberían hacer reflexionar sobre el estado del arte público y sobre la inclusión de herramientas similares en las políticas públicas actuales. Generar debate y controversia a fin de revisar lo que actualmente se está haciendo al respecto en otras latitudes y establecer una hoja de ruta que tenga como objetivo principal la correcta integración de arte contemporáneo en el entramado urbano, permitiendo a las generaciones presentes y futuras cuestionarse la forma en la que vemos, escuchamos, pensamos y nos comportamos.

\section{Algunas respuestas:}

\section{— ¿Cómo se seleccionan los barrios en los que se sitúan las obras?}

Los proyectos del Percent for Art Program están vinculados a las obras a realizar en los cinco barrios de la ciudad. El programa busca mantener un ratio equitativo en las diferentes áreas y primar todo proyecto que tenga un mayor impacto para la comunidad y su entorno.

\section{— ¿Hay cesión de derechos de autor al Ayuntamiento?}

Las piezas que conforman la colección del Percent for Art
Program son propiedad de la ciudad la cual se reserva el derecho de utilizar imágenes para promocionar la iniciativa y el programa, no pudiendo hacerlo con fines comerciales. El autor(es) tiene libertad para utilizar imágenes de la obra incluyendo fines comerciales.

\section{- ¿Se catalogan las obras?}

Las obras se encuentran catalogadas dentro del registro de la colección del Percent for Art Program de la Concejalía de Cultura.

\section{$-¿$ Qué vinculación posterior existe del Ayuntamiento con los artistas?}

Los artistas mantienen una vinculación con el programa y participan en cualquier menester que tenga que ver o se relacione con su pieza, principalmente en lo concerniente a futuras restauraciones de la obra o por motivos divulgativo o informativos.

\section{- ¿Pueden volverse a presentar?}

Si bien se busca fomentar la diversidad y dar oportunidad a nuevos creadores, los artistas pueden volver a ser considerados tras cinco años desde la instalación de su última obra.

\section{Notas}

[1] El Federal Art Project posteriormente renombrado Works Progress Administration fue el primer intento de patrocinio de las artes por parte del gobierno de los Estados Unidos, y el más extenso e influyente desde la Gran Depresión de la década de 1930 durante la administración del presidente Franklin D. Roosevelt. El éxito del programa fue en gran medida resultado de su primer director, Holder Cahill, (1880-1960), curador, escritor y gestor cultural, que vio el potencial para el desarrollo cultural a través de lo que sería un programa de ayudas para artistas.

[2] El presupuesto para cada proyecto, proveniente del 1\% del presupuesto de construcción del edificio, espacio u obra civil, y se desglosa de la siguiente forma: Desglose del presupuesto del $1 \%$.

a. $20 \%$ Honorarios del Artista. Cantidad a recibir por el artista(s) por idear la pieza de arte público. Dicho porcentaje no incluye los honorarios de fabricación en caso de que sea realizado por el propio artista(s).

b. $60 \%$ Instalación y Fabricación. Cantidad destinada a la producción y posterior ubicación de la pieza en el lugar.

c. $10 \%$ Gastos Generales. Cantidad destinada a partidas no relacionadas directamente con la producción de la pieza: seguros, documentación, viajes... 
d. $10 \%$ Contingencia. Cantidad destinada a hacer frente a imprevisto o fluctuaciones de precios durante el periodo previo a la instalación de la pieza.

e. Sponsor Agency. Concejalía que gestionará el espacio: Departamento de Parques, Departamento de Transportes, Departamento de Educación... El representante ha de ser un técnico en arte público.

f. Sponsor Agency. Concejalía que financia la obra. En su mayoría esta figura recae en el Department of Design and Construction (Departamento de Obras Públicas) o el New York City Economic Development Coorporation. El representante ha de ser un técnico en arte público.

g. Public Design Commission de la Ciudad de Nueva York, conocida legalmente como la Art Commission es la agencia del gobierno de la Ciudad de Nueva York que revisa obras permanentes de arquitectura, paisajismo y arte que serán ubicadas en suelo público de la ciudad. La Comisión está compuesta por 11 miembros que sirven pro-bono y se reúnen una vez al mes para revisar y votar proyectos presentados por agencias de la Ciudad. Los miembros incluyen un arquitecto, arquitecto paisajista, pintor, escultor y tres miembros independientes, así como representantes del Brooklyn Museum, el Metropolitan Museum, la Biblioteca Pública de Nueva York y Alcaldía.

h. Artist Statement o Declaración de Artista es la descripción del proceso creativo de un artista. El breve escrito tiene como finalidad informar, facilitar la comprensión de la obra y presentar las bases para un mejor entendimiento del trabajo; es por tanto un texto de naturaleza didáctica, descriptiva o reflexiva.

\section{Bibliografía}

HEIN, H. (1996). What is Public Art? Time, Place, and Meaning. Journal of Aesthetics and Art Criticism 54: 1-7

VICTORIA GRIEVE, (2009). The Federal Art Project and the Creation of the Middlebrow Culture. Chicago: University of Illinois.

HAPKE, LAURA (2008). Labor's canvas: American workingclass history and the WPA art of the 1930s. Newcastle: Cambridge Scholars. 113

JACOBS, JANE JACOBS (1961)The death and life of great American cities. New York: Random House.

CLAIRE BISHOP (2006) ed. Participation. London: Whitechapel.

\section{Autor/es}

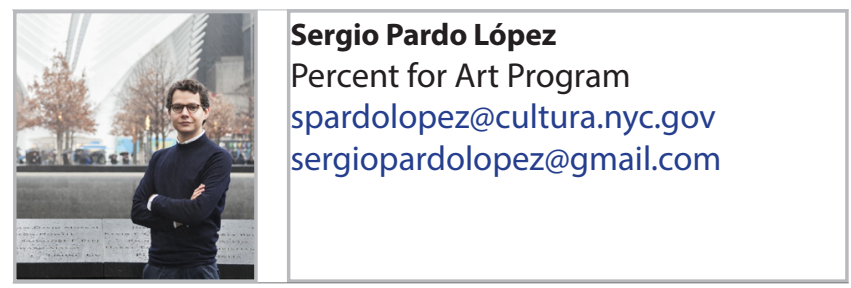

Director de Proyectos del Percent for Art Program de la Concejalía de Cultural de la Ciudad de Nueva York. Arquitecto Superior por la ETSAM de Madrid, visitante del Illinois Institute of Technology (beca Rafael del Pino), MBA Cultural por New York University (beca Fulbright), y ctual doctorando en el programa de Arquitectura, Diseño, Moda y Sociedad de la Universidad Politécnica de Madrid, ha venido desarrollando una trayectoria vinculada al mundo del arte desde una óptica multidisciplinar. En tal sentido ha participado en el comisariado de proyectos en prestigiosas instituciones como la Colección Peggy Guggenheim de Venecia, el Pabellón de España en la 10a Bienal de Arquitectura de Venecia, la Fundación Canal de Isabel II, la Casa Encendida de Madrid o la gestión de la Colección Lola Garrido. Ha sido conferenciante invitado en diversos foros como: Cornell University, New York University, Universidad de Navarra o Christie's. 